\title{
Mapping the Volkswagen Diesel Dupe Crisis, its Implications and Sustainability of their Responses
}

Chong Kok Wai, Tan Seng Teck, Ma Junkai, He Lu, Wong Chee Hoo, Alex Hou Hong Ng, Toong Hai Sam

To Link this Article: http://dx.doi.org/10.6007/IJARBSS/v11-i5/9919 DOI:10.6007/IJARBSS/v11-i5/9919

Received: 13 March 2021, Revised: 19 April 2021, Accepted: 07 March 2021

Published Online: 17 May 2021

In-Text Citation: (Wai et al., 2021)

To Cite this Article: Wai, C. K., Teck, T. S., Junkai, M., Lu, H., Hoo, W. C., Ng, A. H. H., \& Sam, T. H. (2021). Mapping the Volkswagen Diesel Dupe Crisis, its Implications and Sustainability of their Responses. International Journal of Academic Research in Business and Social Sciences, 11(5), 211-226.

\section{Copyright: (c) 2021 The Author(s)}

Published by Human Resource Management Academic Research Society (www.hrmars.com) This article is published under the Creative Commons Attribution (CC BY 4.0) license. Anyone may reproduce, distribute, translate and create derivative works of this article (for both commercial and non-commercial purposes), subject to full attribution to the original publication and authors. The full terms of this license may be seen at: http://creativecommons.org/licences/by/4.0/legalcode

Vol. 11, No. 5, 2021, Pg. 211 - 226

Full Terms \& Conditions of access and use can be found at http://hrmars.com/index.php/pages/detail/publication-ethics 


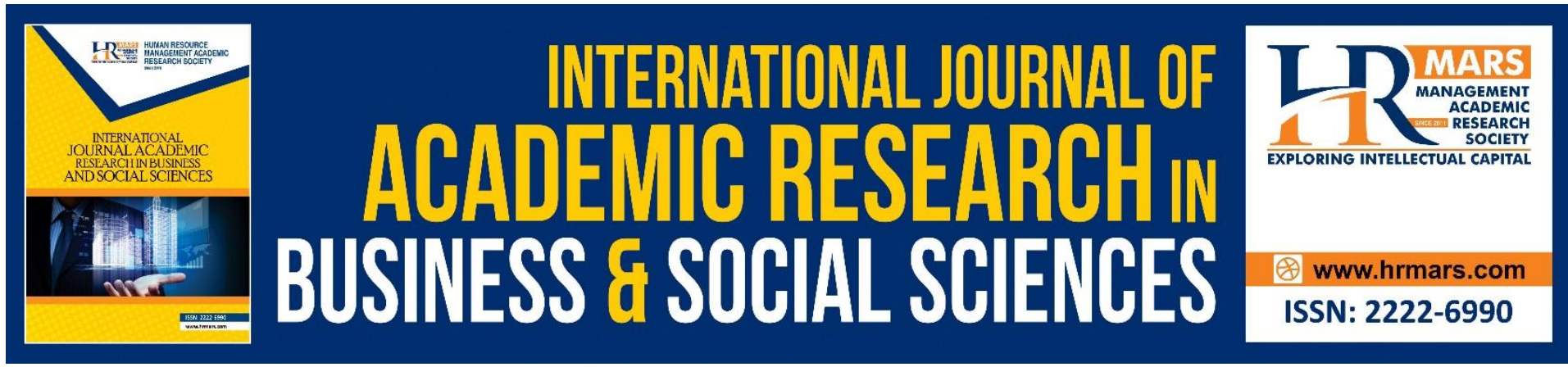

\title{
Mapping the Volkswagen Diesel Dupe Crisis, its Implications and Sustainability of their Responses
}

\author{
Chong Kok Wai, Tan Seng Teck, Ma Junkai, He Lu, Wong \\ Chee Hoo, Alex Hou Hong Ng, Toong Hai Sam
}

Faculty of Business, Communications and Law INTI International University, 71800 Nilai, Negeri Sembilan, Malaysia.

Email: kokwai.chong@newinti.edu.my

\begin{abstract}
The Volkswagen 'Diesel Dupe scandal' is no stranger in the automobile industry and the entire business community. This scandal is a fruitful reminder on the extent to which corporations can blatantly flout regulations and distort business ethics and morality. Many writers have written on this crisis and of course from various perspectives. Some approached the crisis from a technical standpoint, reviewing the 'marvel' of Volkswagen's technological manipulation. Others approached the scandal from the standpoint of moral philosophy, demarcating the firm's inherent immorality that has detracted the ethical values of the company. Journalists conversely have promulgated the scandal as a sensational headline in many reports. Of course, these writings are often detached with some paying overload responses to philosophies, others on strategic woes and a handful addressing the scandal from a techy perspective. This writing differs from previous works and attempts to fuse and associate the philosophical and strategic issues of the scandal to produce a remarkable analysis. Firstly, by improvising Andy Grove's 'strategic dissonance' theory, this work attempts to plot the precise point in which Volkswagen's diesel crisis relent a tsunamic moral repercussion. An improvised version of Grove's model contributes to understanding the philosophical intricacies of this scandal capable of understanding the phenomenological moral repercussions in Volkswagen. Secondly, by using this phenomenological understanding, the current authors were able to accurately charter the precise impacts of the scandal and of course lastly to instill a distinctive evaluation on the effectiveness of Volkswagen's crisis response strategies. The main contribution of this paper expounds beyond merely theoretical implications, but more importantly, the ability to connect and associate the philosophies of ethics with strategic implications.
\end{abstract}

Keywords: Diesel Dupe Crisis, Implications, Sustainability of Responses

\section{Introduction, VW from Greatness to Downfall}

The Volkswagen (VW) "Diesel Dupe" crisis is one that shocked the world. It took the world by surprise how a legally abiding and ethically reverential corporate giant could blatantly lie, 
defraud and betray those trusts that others have bestowed upon them. Dubbed as the "scandal of epic proportions" (Cavico \& Mujtaba, 2016), studying VW and their response to this crisis is an excellent gateway to understanding the role of a crisis, sense-making CSR, reflexive organisation change and moral transpose a firm encounter when faced with an unprecedented crisis. This paper examines the "Diesel Dupe" crisis and particularly comprehending how the crisis unfolded to project a keen insight on how an ethical crisis of this proportion could have decisively impacted the strategic, cultural, anthropological and ethical trajectory of this automobile giant. This paper is grounded in providing pioneering insights by systematically depicting the convergence and transposition of ethical evolution and changes within VW by plotting their responses and reactions towards the crisis using a remodeled "strategic dissonance" approach.

VW had grown dynamically, and in 2015, they even overtook Toyota Motor Corporation as the largest car manufacturer in the world. This evidenced the achievement of VW's ten-year goal, which was set in early 2007 engendered by Martin Winterkorn (Rhodes, 2016). By 2018, VW had envisioned to be the single most profitable automotive company globally, an ambition that sparked scepticism even with their most ardent shareholders. VW was set to push ten million units annually, with a pre-tax revenue of $9 \%$ with an arsenal of the most satisfied customers in the entire automotive industry. VW boasted its ecological prowess and lauded its ethical business approach. In 2012, VW was recognised as the most outstanding winner of the 'Ethics in Business Award' (Rhodes, 2016). VW set an outstanding example of how profit and environment protection can coexist.

All these collapsed when in September 2015, the United States Environmental Protection Agency queried VW's emission tests and accused Volkswagen violating the Clean Air Act. VW was caught for installing 'cheat devices' in 490,000 of their diesel-powered vehicles in the U.S.A. The device could detect when a car is being tested and control its $\mathrm{Co} 2$ emission to their lowest degree. At normal driving conditions, the cheat device would switch off and performance and of course Co2 emission will increase by 45 times. VW cascaded into a turmoil of global scandal. Once hailed as an ethical company, VW is now accused of fraud, lie and its reputation is tattered. VW lost a third of their market share values within a week of the announcement and Martin Winterkorn resigned pending criminal investigations.

The VW diesel scandal provides a monumental subject for this study. The scandal involves tangible and intangible impacts particularly the drastic organisation change and moral transpose VW experienced. Post-crisis, VW showed clear evidence of an ethical struggle and its pervasive impact on the corporate giant. A statement of their 2017 annual report clearly epitomises this struggle where it asserts that the firm was facing a dual challenge which points to the continuous impact of the diesel crisis and internal process that need to be changed. The statement gave powerful evidence to show that the impact of the crisis is spreading and the strategies were undertaken to decrease the impact is largely unsuccessful. The phrases "We have not yet surmounted the diesel crisis" indicates that VW has not recovered from the impact of the diesel crisis. "these initiatives, as well as the impressive commitment of our workforce to this process of change, must take a back seat when news of the misconduct and poor judgments that unfortunately took place within our Company once again becomes public" shows that the VW's strategies used to solve the impact of the crisis has been ineffective (Volkswagenag.com, 2017). The statement made it clear that the main proponents of the crisis are inextricably linked to social charter and VW has clearly violated the minimum value of universalistic values and ethics (Teck et.al, 2020) which triggered what Andy Grove 
(1998) terms as a "strategic dissonance", reflecting a firm's business value is detached from social exceptions.

Through analysing the statement, the objective of this work is to answer three pertinent questions. Firstly, exploring the factors that brought about the crisis and the impact of the diesel crisis on VW. Secondly, it will evaluate the effectiveness of VW's strategies in response to the ethical, public communications, strategic decision making and company management structure crisis. Finally, we will give suggestions from a few major dimensions of the structure, culture, rapport, reputation, and future business model.

\section{The Complexities of Identifying the Triggering Factors of VW's Crisis}

The VW scandal consists of a series of complicated events. Therefore, it might not be possible to enlist all the events directly as it may not be sufficient to explain the 'precise triggering point of the crisis'. However, by using the 'punctuated equilibrium model' advocated by Teck et.al (2017), this paper examines the crossover point of VW in their transposition of ethical behaviour from utilitarianism to universalism. The 'punctuated equilibrium model' dictates that a firm typically usurps a utilitarian approach in business. However, there is a minimum ethical value that the firm needs to abide and any breach of this universalistic ethics would result in a punctuated backlash where the firm could suffer an ethical crisis. This paper now addresses the second question, that is, what kind of ethical transpose do firms experience when they encounter a crisis? To answer this question, it is vital to address the trajectory of an organisation's moral transposition i.e. transforming from what to what and from where to where? To address this point reader (s) must understand the fundamental theories of ethics. For simplicity, there are two main theoretical divisions of utilitarianism and Kantianism often termed as 'rival ethical principles' (Shaw et al., 2015) conveniently labelled as the 'consequentialist' and 'non-consequentialist' approach. Shaw et al (2015) for example laments that such division is a common and simplistic measure and is capable of providing a clear resolution to specific ethical dilemmas. Shaw et al (2015) argue that it is a common practice to group these theories as consequentialist and non-consequentialist. This is simply a way of separating those theories that are concerned primarily with outcomes (or consequences) and those theories that are primarily concerned with particular or general principles or rules on which to base our decisions or resolve dilemmas. Simplistically, Kantianism is a purely deontological measure grounded on duty-based ethics. Widely known as the non-consequentialist approach, its founder Immanuel Kant (1724 - 1804) lamented that the application of morality must be non - contradictory, consistent and based on goodwill. Kant insists that moral maxims must be categorically imperative so that their values must be without contradiction and presents its purest sense. A pivotal point is that one must treat "humanity as an end and never a means to an end" and that a rule must be universally acceptable (Teck et al., 2018).

Modern theorists approved this point. The book titled "Purpose, the Starting Point of Great Companies" written by Mourkogiannis in 2006 wrote that the 'real value' of business organisations is an altruistic sense to solve human and social problems. Thus, the purpose of an organisation is to provide solutions to existing human problems where profit is a collateral benefit. Clearly, this means that ethics are ingrained in business. Business organisations must fulfil their underlying ethical duty to society, which forms the cornerstone of a business foundation. 
Utilitarianism expounded by Bentham (1748 - 1832) and Mill (1806 - 1973) conversely postulated that one should always act to produce the greatest ratio and balance of good (pleasure) over pain (sufferings). An action is moral if it produces the highest pleasure for the greatest number. Utilitarianism measures the validity and morality of an act wholly dependent on the "consequences as opposed to the circumstances or the intrinsic nature of the act or anything that happens before the act" (Shaw et al., 2015). Utilitarianism, which is linked to self-interests, invariably propels the economic success of the society. Adam Smith in the Wealth of Nation (1776) precisely articulates the correlation between utility and capitalism that:

...pursuing his self-interest, he frequently promotes that of the society more effectually than when he really intends to promote it (Wealth of Nation 1776).

The foregoing review illustrates a stark difference between the moral standards of universalism and utilitarianism. There appears an unbridgeable gap between the two diversity of moral values. Due to this immense difference in moral dichotomy, authors generally agree that it becomes impossible (or at least near impossible) to reconcile these moral controversies. Shaw et al (2015) explain these moral contradictions where he mentioned:

Theoretical controversies permeate the subject of ethics and, as we have seen, philosophers have proposed rival ways of understanding right and wrong. These philosophical differences in perspectives, emphasis and theory are significant and can have profound practical consequences.... but obviously it cannot settle all of the questions that divide moral philosophers... (pp. 92).

Shaw's opinion is misleading and a contradiction. It deluded firms to believe that there is only 'one best way' of measuring ethics. Firms are misguided to undertake one perspective in the sacrifice of the other. Teck et al (2018) in their work addressed the point that a crisis can trigger a firm's moral transpose from utilitarianism to Kantianism. Their work specifically highlighted VW's moral transpose during in the diesel crisis. The authors wrote:

...despite the unembellished distinctions between the two concepts they can be inextricably linked in context. While it is a common and regular assumption that business firms normally usurp a utilitarian business value, firms are estopped in protruding that value when they breach the minimal content of morality. That would result in a punctuated equilibrium which in turn forward serious business repercussions for the firm. Most firms will respond by resorting to embrace universalistic and categorically imperative moral values (Teck et al., 2018).

However, while Teck et al's work in 2018 argued the possibility of a moral transpose in business firms, they have not provided a model to illustrate how this transpose is possible in reality. This thesis fills this literature gap. This paper argues that Kantianism and utilitarianism are not mutually exclusive but mutually inclusive. This paper aims to examine the point of convergence and mutual inclusivity between utilitarianism and universalism. To explain this, the current author devices the 'ethical dissonance modal' (EDM) framework in Diagram 1 below. 
Diagram 1: Ethical Dissonance Model and Organisational Moral Transpose Source: $\quad$ Adapted from Burgelman and Andy Grove (1996)

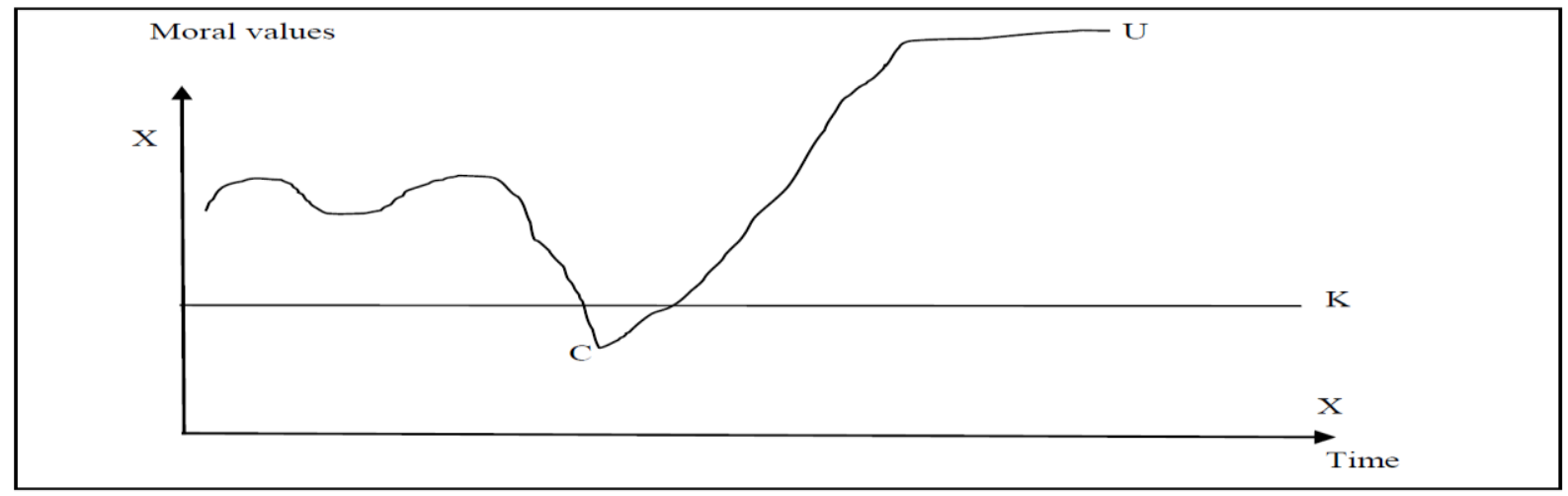

The curve $U$ represents the utilitarian ethical values of a firm throughout different times $X$. One could observe that $U$ is nonlinear but presents an inconsistent curvature of utilitarian relative ethical values. $U$ represents the utilitarianism and relative ethical values of the firm measured through the hedonism calculus of pain and pleasure. The standard and linear horizontal line denoted as $\mathrm{K}$ represents a categorically imperative and universally accepted Kantian value. $K$ lays the fundamental and minimum content of moral values that a firm must adhere to. Over time, a firm's moral value dips and breaches the Kantian minimum moral content in $\mathrm{K}$ as denoted as $\mathrm{C}$. In that case, an 'ethical inflection point' ensues and a firm will experience backlash. In turn, the firm then increase its moral value as seen in the upward soar in $U$. The upward soar represents a sober renewal where firms experience reflexive change and rejuvenate their moral values.

Diagram 1 above displays the punctuated value of the diesel crisis. It describes the important point since VW's scandal was exposed. Diagram 2 below presents a special model to examine the precise events that occur in the unfolding saga of the masses. The horizontal line marked "Minimum value" represents the constant of the lowest ethical standards that the public must abide by. This represents the imperative and universally accepted Kantian values. The curve represents the fluctuating utilitarian values that the public exercised during the crisis. Points 2005, 2014, 2015, 2016 and 2017 represent the three bright spots of the crisis. It is worth noting that although point 2014 and point 2015 are relatively close to breaking through Kantian's content, point 2016 (highlighted in blue) fell below the minimum value.

This paper uses the punctuated equilibrium theory to describe the chronology of crisis. It is a good way to show the most decisive event, which led to the exposure of the scandal. This approach is consistent with the literature on crisis management, which emphasises the need to identify alpha triggers in specific crises. This revised model provides a succinct and practical amalgamation of utilitarianism and Kantianism. This EDM framework is novel and chartered an unprecedented connection between utilitarianism and Kantianism. Diagram 2 below illustrates VW's moral transpose using an EDM approach. 
Diagram 2: Scatter plot of minimum value of chronology of diesel crisis

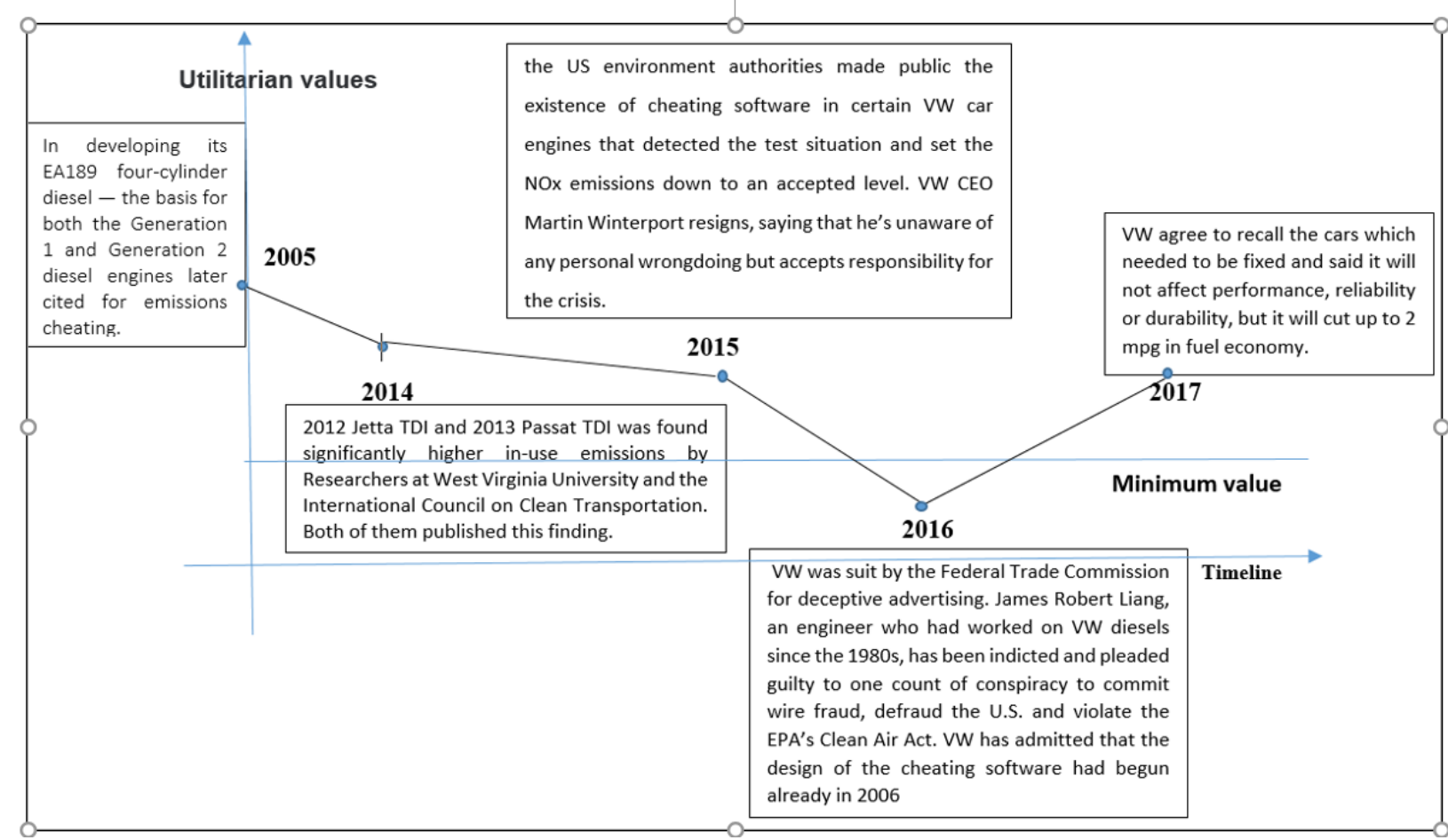

Kant (1785) argues that rational existence cannot be treated as only a means to an end, it must also always be regarded as ends in themselves, requiring that their legitimate motives be equally respected. This comes from Kant's claim that reason motivates morality: it required us to respect reason as the motive for all beings, including others. The fraudulent problem of the detection data of the VW Group violated the corporate social responsibility principle, which broke the minimum norms of law and harms the sustainable development of society. It made the behavior of the VW company considered to be only for the benefit of the market and had no sense of responsibility. VW's emissions fraud or cheating crisis began on September 18, 2015, when the U.S. environmental agency disclosed that some of VW's engines contained cheating software that detected testing conditions and reduced nitrogen oxide emissions to acceptable levels.

Authorities have been in touch with the carmaker since 2014, but the company has mainly tried to deny that there is a widespread problem and that the issue is confidential. Later in 2016, the company admitted that the design of the cheating software had begun in 2006. In the fall of 2015, US authorities found that more car engines were fitted with the same software as those tested for the first time. In the summer of 2016, the US authorities found more software with similar functions.

The VW crisis had emerged other sub-problems, and the amount of media reports and social media information reaches its peak. The crisis cost VW more than 18 billion euros and damaged its reputation. The former is because the company must pay fines to the U.S. government and other agencies, recall and compensate for vehicle costs, customer packaging and lost market share. VW shares also fell sharply in the stock market, leaving shareholders disappointed with management. 
The crisis was caused by product defects and the dissemination of information about problematic products through social and traditional media. Social media seems to be following and spreading this information as well. We assume that the public follows a crisis communication strategy, which is to admit nothing until caught. In this case, only the authorities can reveal emissions cheating. Therefore, companies don't deny this when interacting with car owners or other stakeholders on social media sites. They can only try to comfort, repair and compensate stakeholders for their monetary losses. VW paid compensation only to the owners of WV diesel vehicles in the United States, but not to other owners. Except for poor service quality, long response times on twitter or email also appear to be a major problem in India. This kind of thing is a problem for VW and often leads customers to switch to the competitors.

\section{Measuring the Exact Impact in VW's Diesel Crisis}

The diesel crisis brings extensive losses at the national and international levels. VW's as part of German national carmaker play important role in the total German economy which has burdened the county, and it has increased the political pressure and exposed the flaws in the entire European automotive testing system. It is hard to measure the exact losses caused by the crisis and in this paper, but the authors will be focusing on three main impacts within the VW organization, namely the impact on VW's reputation and integrity damages, financial \& market capital, and management structure \& corporate culture caused by the crisis.

\section{Reputation \& Integrity}

VW's reputation and integrity suffered the most significant damage since the crisis was exposed. The scandal heavily affected the social, environmental, and caused frustration and disappointment from the public. By the end of 2016, VW cars with defeat devices had produced additional toxic pollution that caused the premature death of roughly 60 individuals merely in the United States. From the year 2008 to 2015, 428,000 VW and Audi diesel cars pumped out nitrogen oxide 40 times more than it was allowed by the Clean Air Act. It is estimated that with six years VW and Audi diesel produced an excess of 36.7 million $\mathrm{kg}$ of nitrogen oxide to the environment. Nitrogen oxide is a primary element of particulate and smog matter which paves the ground for various disease namely heart disease, premature death, bronchitis, and respiratory and cardiovascular disease. The excess of pollution from VW vehicles participated directly in 31 and 34 chronic bronchitis and admission of respiratory and hearth cases respectively in the United States (Aazanin, Mansouri 2016). Moreover, VW poorly handled public communications especially the way they managed social media protests and lacked appropriate strategies plan in managing the situation (Zhang, 2017). These have further hurt the company's reputation.

\section{Financial \& Market Capital}

The sales of diesel vehicles have fallen sharply. Along with the continued impact of the crisis, the United States, Brazil, South Korea, India, and other countries have fined the VW for about 14 billion euros. With the stock price crash, VW has recalled and rectified vehicles worldwide, as well as claims from consumers and investors, the total loss is estimated to be as high as 65 billion euros. The sharp down of VW's share price has caused its market value to shrink by 30 billion euros. 
The biggest problem the company could face is a 15.8 billion euro fine. As a direct result of the scandal, the company has announced changes to its costs. Initially, the company announced $\$ 1$ billion in cuts to its research and development budget. Then they decided to switch all of their future cars to electric ones. The company now plans to develop a new scalable power architecture, known as MEB, for the new generation of electric vehicles with a range of 250-500km (Bojan et al., 2016).

When sales of VW were affected, they have announced that the bonus of chief management will be reduced substantially. This leads to a considerable diminution of variable remuneration. The reduction in the bonus will include management board and also a group of executive positions assisting the CEO to operate the company's daily routine.

\section{VW's Management Structure \& Corporate Culture}

HR chief of the VW Group, Karlheinz Blessing said that their corporate structure would be impacted and completely changed after the diesel crisis. They see the need to establish a new accountability mechanism. The management structure, corporate values, and principles have been re-examined to deploy the company's leadership transformation (Andreas, 2017). Since the explosion of the diesel car crisis, the company has elected a new CEO and re-appointed the directors of the five departments to make the rights more dispersed. The new internal management structure of $\mathrm{VW}$ is being streamlined, speeding up the decision-making process, strengthening internal information communication and supervision, and improving efficiency. The crisis has deeply impacted the corporate culture change and the effectiveness of such change might not equitable to turnaround the damages.

\section{A Critical Evaluation on the Effectiveness of VW's Crisis Management}

The VW diesel crisis has caused serious damage and threat to VW itself and society. In view of the impact of this crisis, the measures of management and responses of the VW Group had not sufficiently effectiveness, so that they had not yet surmounted the negative influence from this diesel crisis for which they are responsible. The crisis from this diesel car incident was shown on different levels and we will be discussing how VW managed its ethical, strategic and crisis.

\section{Evaluating of VW's Responsiveness in Ethical Crisis Management}

The investigation published by Researchers at West Virginia University and the International Council on Clean Transportation in 2014 shown that the emissions of various diesel vehicles produced by the VW Group were seriously exceeded. After that, the company had always denied that it has any misconduct and blamed the unknown technical problems as the reason for emission. The VW believed that even if the incident would be revealed, they could pay a fine to end the crisis. When the incident was further fermented, the VW still did not admit that they developed special devices for fraudulent purposes. After the US Environmental Protection Agency dismantled it, this ethical crisis reached a level that was difficult to control by the VW Group.

In the face of this ethical crisis, I think the reaction of the VW has failed. In comparison, as one of VW's main competitors, BMW chose to develop diesel cleaning technology with high costs, such as AdBlue. From the beginning, VW chose to abandon the research and development of new technology and designed the suppression device, to save about 4.8 
billion dollars in technology licensing fees. But VW has paid more than 20 billion dollars in fines for the diesel scandal cumulatively. This behavior of the VW violates laws and regulations, it continuously conceals the relevant facts of the vehicles and deceives the public after the crisis, which violates the integrity and corporate behavior standards and ethics.

This strategic decision has further demonstrated the company's unethical business culture. With the release of more and more information, this crisis has shown that senior managers of the VW Group have undermined basic ethical and legal norms. They know that this behavior might bring great risk to people's health and the environment, but they also gave up the standard because of profits. These basic ethical principles seem to be obstacles to the pursuit of interests by VW's senior managers.

\section{Evaluating VW's Responsiveness in Public Communications Crisis Management}

VW also has shown that the company was not prepared for this major crisis. So, their strategic deployment was disordered. In the external information communication after the crisis broke out, the vague attitudes and explanations of VW triggered more social protests. Their response to the crisis reflects that they still don't know the right way out and have not found the most appropriate strategic plan.

VW only admitted their wrongdoings only after it was caught and the official statement or apology statements by the management was not immediately published. Unlike Samsung, the company admitted promptly on Note 7 and washing machine faulty and issue apology statement in newspaper and video form from digital media. VW has not just responded slow and they also have removed posts and replies by the public in social network platforms namely, Twitter and Facebook page (Zhang, 2017). These are the worst actions which were badly hit the company's reputation and integrity for being not open, honest, and not accountable for the mistakes.

In terms of selection of media, VW has employed delayed post-crisis communications through varieties of media like online press statements, press conferences, letters to affected stakeholders and there was a lack of timely communications, immediately issuing online press releases and news conferences. VW's message is formal, detached and lack of transparency and empathy. In their public speech, the management's body language reflects no remorse for wrongdoing. VW tends to be more business-oriented and guided by financial implications. VW is not able to rebuild trust and repair the damaged image through its effective public relations crisis management.

\section{Evaluation of VW's Responsiveness in Strategic Decision Making Crisis}

VW's mistakes in strategic decision-making also caused a credibility crisis for the company. In 2015, VW's new CEO released a strategy to recall vehicles related to the diesel crisis worldwide. But in terms of fines, the VW Group has shown different decisions for the US and European markets. While the public acknowledged cheating in the United States and provided compensation to those car owners. And it claimed that its actions were not illegal under the EU regulations, so, VW would not provide compensation to European car owners of diesel vehicles. This decision made the VW brand more controversial in Europe, and many consumers thought they were despising European car owners. Even when the European Commission asked the VW to reconsider about compensation, they rejected the proposal by using laws and regulations differences as an excuse. Therefore, there was fewer litigation in 
many countries in Europe. Not only did VW not actively take remedial measures after the crisis through strategic arrangements, but also seeking various pretenses to evade compensations as much as possible. This further embodies the fact that VW takes egoism as the core of the enterprise and never considers the interests of consumers and the public. The strategy also reveals that VW has continually evaded various penalties and has not taken the initiative to take responsibility.

\section{Evaluation of VW's Responsiveness in Company Management Structure Crisis}

In 2011, VW appointed an organizational Chief Compliance Officer (CCO) to set up a new compliance department. The purpose was to monitor and manage employees with compliance issues within the VW and reduce the company's ethical risk. However, this department did not find the compliance issue of diesel vehicles, nor prevent the explosion of the VW diesel scandal. It embodied that the work of this compliance department of the VW was ineffective, which also reflected the shortcomings of the management model of VW's CEO and CCO.

VW uses a command-based corporate management structure and leadership style. The previous CEO of VW, Martin Winterkorn, advocated an authoritarian leadership style, so the entire company was operated in such an authoritarian management model. This made the company's employees never call into question for the decisions of senior leaders and strictly required their subordinates to complete the assigned tasks. VW's top managers were concerned project results more than its process, which directly led some managers to use the mean of cover and deception to avoid work failure. Such corporate culture was a great obstacle for the long-term development of VW. After the crisis broke out, the VW Group dismissed some relevant responsible persons. It just eliminated some negative effects on the surface but did not regain the trust of consumers. Because they did not fundamentally change the corporate culture and management model, which made the VW Group's strategy at the management level do not effectively solve the crisis.

The crisis reflected in the management aspect is the most important to VW. VW's vision is "We are the world's leading sustainable mobility provider." And its mission is "To provide customized mobile solutions for customers." Such statements are very general and do not reflect the company's outlook on the future clearly. This simply displays that VW's business direction is customer-oriented, but the group's objective lacks clear core values and ideas. The mission and vision often guided employees to more specifically understand the value of the organizational business and find the right way to achieve it. During these years, VW did not emphasize the company's vision and mission, nor did tie them closely to the company's business strategy. This made their employees lose understanding of the corporate culture and lose the corresponding code of conduct. Therefore, this crisis also showed that the mission and vision of VW had a defect.

Then, after the crisis broke out, VW did not fundamentally consider the solution to the crisis, which was the change in vision and mission. A similar example came from Baidu in China. Baidu Inc., a well-known multinational Internet company, had the mission that had not to be changed since the company founded, which was "Provide the best and most equitable way for people to find what they're" (Baidu Corporate Social Responsibility Report, 2016). In the case of the death of Wei Zexi in 2016, Baidu was strongly criticized by Chinese public opinions 
and was regarded as unfinished corporate social responsibility. The relevant vice president was also dismissed for violating professional ethics and harming the company's interests. After the incident, the founder of Baidu who is Li Yanhong released a formal internal open letter, as well as reflected and had the prospect of the internal organization and corporate culture. In 2017, he firstly updated his corporate mission to "To make a complex world simpler through technology", thereby promoting the transformation of the company's strategy.

\section{Recommendations}

Based on the discussions in the earlier part of this paper, there are few recommendations that VW may consider for future business improvement. There are many studies and recommendations proposed by many researchers which mainly surrounding VW's business future model, crisis management capability, social responsibilities, corporate governance, etc. We here would like to propose a 3Rs dimensions namely REFORM, REBUILD \& REBOOT which we think will be helpful to VW's short-term and long-term business improvement.

\section{Reform Management Structure \& Corporate Culture}

Strengthening the management structure is different from a reform movement. As discussed earlier, VW appointed a new CEO and re-appointed five key directors which aim to strengthen their efficiency and supervision. But to reform the structure, VW shall dismiss all key members who were involved in the scandal namely, VW former chairman of the board of directors Martin Winterkorn who first lied about the scandal. VW shall draw a clear line between the old and new leadership. They need to gain public trust through a brand new leadership team. In terms of corporate culture, VW shall emphasize integrity, transparency, and social value. Businesses' purpose shall not be just for profit nonetheless must be redefined as creating shared value (Porter, 2015). VW shall show to the world that they are concern about shared value and committed to corporate social responsibility (CSR). Carroll's CSR pyramid illustrated in Diagram 3 argued that CSR is built on the foundation of profit or economic responsibilities followed by legal responsibilities, ethical and philanthropic options. (Seymur, 2014). The diesel crisis reflected that VW was neglected legal and CSR requirements and they shall align their corporate culture movement towards CSR which will bring positive social value to the community.

Diagram 3: Carroll's CSR Pyramid

Source: $\quad$ Seymur MG. (2014)

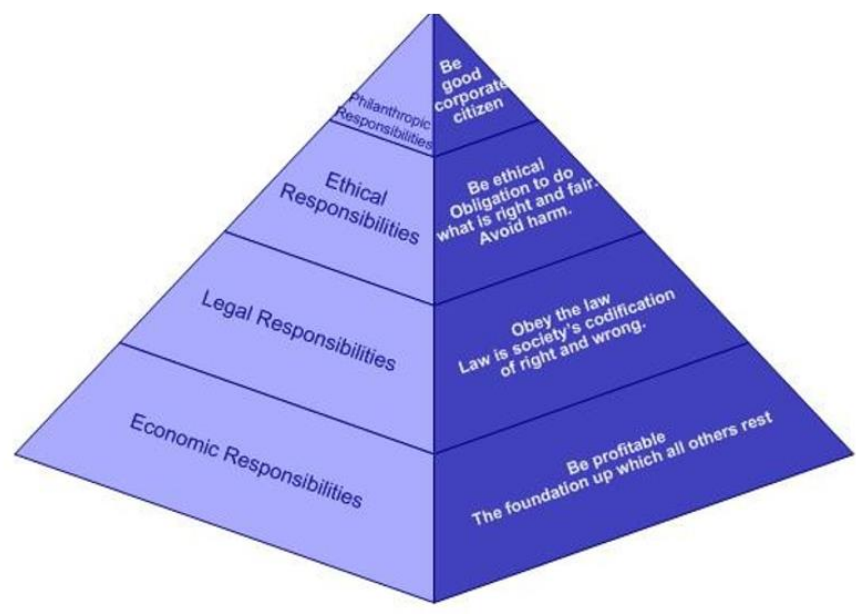




\section{Rebuild Rapport \& Reputation}

VW's scandal deeply affected the client's loyalty and brand preference. Worldwide dealers are part of the impacted party when VW's clients starting to buy other bands instead of VW affiliated brands. Dealers struggle with low sales volume and profit margin (Nazanin, 2016). Dealers are VW's key stakeholder as they are the championing the sales, therefore, the company shall provide supports to the dealer's network through various programs such as formulate new pricing strategy and structure, establish new incentive and bonus system, and deploy new market positioning strategy to gain competitive advantage.

Rebuild rapport with dealers is crucial and so do the clients or community. VW shall strengthen their rapport building with the community through collaboration with government, universities, scientific agencies, researchers, and other NGOs in environmental sustainability research and campaigns. VW shall consider inserting greater investment or grant to the community in the green movement. VW shall prove to the community that they are committed to creating social value and they will not be the same as the VW in the past. To move to farther step, VW may consider committing a bond with European Commissions where if the scandal happens again VW will pay a huge bond as a penalty. This will further reflect their seriousness and assurance in practicing ethical business conduct.

Lastly, VW must learn from their past weaknesses especially public relations and communication management skills. The company shall act fast and immediate in responding to society promptly. VW shall wisely utilize social media to strengthen their rapport with public and marketing strategy. Chloe West (2019) suggested six examples of successful social media marketing often used by many companies and there are four strategies that VW could consider. Firstly, use user content. Positive content posted by users will increase the company's publicity and brand reputation. Secondly, humor content which will attract more viewers and create greater bonding through real-time interaction. Thirdly, cross channel marketing which aims to reach a bigger pool of potential clients through multiple social media channel. Lastly, with the help of Chatbot to enhance engagement.

\section{Reboot Business Model}

VW's diesel crisis might not be easily forgotten by the world and rebrand strategy potentially helpful to reboot the business. Arthur Andersen (AA) is an example. When AA was found guilty of improper auditing in the year 2001 and forced to surrender $r$ its audit license, Accenture PLC was formed. Accenture new brand focus on shaping clients' future. The name changed enables the company to regain its market share and established a new business brand (Business Insider, 2013). VW may consider a new brand name aligning the future business model and corporate mission \& vision.

Looking at the future trend of the green movement, VW may venture into green and renewable power business model. The new business model could be built towards the Green Enterprise principle. As a Green enterprise, a holistic and comprehensive green strategy must be established. An environmental sustainability team or officer must be appointed to govern the green policy and to supervise the progress. The enterprise could take the Tactical Incremental approach, Strategy approach or Deep Green approach as part of their effort in greening the ICT (Murugesan et al., 2012). 
VW shall focus on research and development of environmentally friendly products such as electric cars and hybrid cars. VW current investment in electric cars is relatively small and Jack Ewing (2019) reported in New York Times that VW aims to build 22 millions of electric cars by 2028 though recognizing the risk of acceptance by the buyer and challenges in gaining bigger market share with the existence of giant players namely Tesla, Nissan, Toyota, etc. Besides, VW shall find solutions to reduce global carbon dioxide emissions less than $1 \%$ or even $0 \%$ to set the best benchmark in the industry.

\section{Conclusion}

Volkswagen's diesel crisis has caused a huge shock to the global automotive industry. This crisis proves that ethics is absolute and not relative. For the satisfaction of the status quo and vested interests, many companies are taking risks and challenging social ethics. The act of quietly conniving in order to catch up with competitors has already shown that companies have begun to cross the core of ethics and break through the bottom line of value. In addition to that, strong competition makes a lot of companies continue to make ambitious attempts in order to gain more advantage and create greater reputational risks. Such a crisis also gives the public a good reason to rethink how to deal with corporate illegality and loss of ethics. It is easier to avoid a crisis than to try to remedy and solve problems after the problem. If companies are no longer focused on how to achieve the unreasonable aggressive growth targets set by management, but rather how to strive to achieve the ideals of the business, Volkswagen will not fall into the current embarrassment. The Volkswagen now needs to take steps to reduce its arrogance, make cultural changes, and then perhaps be able to inject vitality into its future.

\section{References}

Andreas, C. (2017), Culture change at VW may take time, HR chief says [Online]. Available at: URL https://www.reuters.com/article/us-volkswagen-emissions-culture/culturechange-at-vw-may-take-time-hr-chief-says-idUSKBN1712D8

Puffer. (1998), Global executive: Intel's Andrew Grove on competitiveness. Academy of Management Perspectives, 13(1), 15-24. Puffer, S. M. (1999). Global executive: Intel's Andrew Grove on competitiveness. Academy of Management Perspectives, 13(1), 1524.

CSRBaidu.com. (2016), Baidu Corporate Social Responsibility Report, 2014-2016 [Online] Available at : http://csr.baidu.com/Uploads/File/2018/04/17/u5ad59c6cb6f67.pdf

Bojan Georgeevski and Anas AlQudah. (2016), The Effect of the Volkswagen Scandal (A Comparative Case Study). Research Journal of Finance and Accounting www.iiste.org ISSN 2222-1697 (Paper) ISSN 2222-2847, Vol.7, No.2, pp. 54-57. Georgievski, B., \& Al Qudah, A. (2016). The effect of the Volkswagen scandal (a comparative case study). Research Journal of Finance and Accounting, 7(2).

Burgelman and Grove. (1996), Strategic dissonance. California management review, 38(2), pp.8-28. Burgelman, R. A., \& Grove, A. S. (1996). Strategic dissonance. California management review, 38(2), 8-28.

Business Insider. (2016), 7 Companies That Changed Names To Save Their Brand. [Online] Available at: https://www.businessinsider.com/7-companies-that-changed-names2013-2?IR=T.

Cavico and Mujtaba. (2016), Volkswagen emissions scandal: a global case study of legal, ethical, and practical consequences and recommendations for sustainable 
management. Global Journal of Research in Business \& Management, 4(2), pp.303-311. Cavico, F. J., \& Mujtaba, B. G. (2016). Volkswagen emissions scandal: a global case study of legal, ethical, and practical consequences and recommendations for sustainable management. Global Journal of Research in Business and Management, 4(2), 411.

Cho, E. (2015), Cronbach's Coefficient Alpha: Well Known but Poorly Understood. [online]ResearchGate.Availableat:https://www.researchgate.net/publication/2764083 09_Cronbach's_Coefficient_Alpha_Well_Known_but_Poorly_Understood.

Chloe West. (2019), 6 standout social media marketing examples for 2019. [Online] Available at: https://sproutsocial.com/insights/social-media-marketing-examples/.

Coombs, W. T. (2007), Protecting Organization Reputations during a Crisis: The Development and Application of Situational Crisis Communication Theory. Corp. Reput. Rev. 10, 163176. doi:10.1057/ palgrave.crr.1550049.

Coombs, W. T. (2002), Assessing online issue threats: issue contagions and their effect on issue prioritisation. J. Public Aff. 2, 215-229. doi:10.1002/pa.115.

Coombs, W. T., Holladay, J. S. (2012), The paracrisis: The challenges created by publicly managing crisis prevention. Public Relat. Rev. Coombs, W. T., \& Holladay, J. S. (2012). The paracrisis: The challenges created by publicly managing crisis prevention. Public Relations Review, 38(3), 408-415.

Ewing, J. (2019), Volkswagen Moves to Rapidly Increase Production of Electric Cars. [Online] Available at: https://www.nytimes.com/2019/03/12/business/volkswagen-electriccars.html. changed

Kant Immanuel. (1785), Thomas Kingsmill Abbott (ed.). Fundamental Principles of the Metaphysic of Morals (10 ed.). Project Gutenberg. p. 39. Kant, I. (1785). Thomas Kingsmill Abbott, ed. Fundamental principles of the metaphysic of morals. Project Gutenberg.

Mourkogiannis, N. (2014), Purpose: The starting point of great companies. St. Martin's Press. Mourkogiannis, N. (2014). Purpose: The starting point of great companies. St. Martin's Press.

Murugesan, S., and Gangadharan, G. (2012), Harnessing green IT. Chichester, West Sussex, UK: IEEE ComputerSociety / IEEE / Wiley. Murugesan, S., \& Bojanova, I. (Eds.). (2016). Encyclopedia of cloud computing (pp. 208-219). John Wiley \& Sons.

Nazanin, M. (2016), A Case Study of Volkswagen Unethical Practice in Diesel Emission Test., Vol 5, Issue 4. SSN-2319-7560. Mansouri, N. (2016). A case study of Volkswagen unethical practice in diesel emission test. International Journal of Science and Engineering Applications, 5(4), 211-216.

NDR. (2016), Die VW-Abgas-Affäre: Eine Chronologie [Online]. Available at: www.ndr.de/nachrichten/ niedersachsen/braunschweig_harz_goettingen/DieVWAbgas-Affaere-eineChronologie,VW892.html.

Porter, M. E. (2015), Share Value Initiative. [Online] Available at: https://www.sharedvalue.org/partners/thought-leaders/michael-e-porter. Porter, ME, \& Kramer, MR (2015). Shared Value - The bridge from corporate social responsibility to corporate strategy. In Corporate Social Responsibility (pp. 145-160). Springer Gabler, Berlin, Heidelberg.

Rhodes, C. (2016), Democratic business ethics: Volkswagen's emissions scandal and the disruption of corporate sovereignty. Organization Studies, 37(10), pp.1501-1518. 
Seymur. (2014), Carroll's Pyramid of Corporate Social Responsibility. [Online] Available at: https://www.linkedin.com/pulse/20140905115337-70750023-carroll-s-pyramid-ofcorporate-social-responsibility. Delete reference

Financial Times. (2016), VW emissions scandal, Financial Times, [online] Available at: https://www.ft.com/vw-emissions-scandal. Delete Red

Volkswagenag.com. (2017), Volkswagen Annual Report 2017. [Online] Available at: https://annualreport2017.volkswagenag.com/ Arora, J. (2017). Corporate governance: a farce at Volkswagen?. The CASE Journal.

WRC. (2016), VW PULLS OUT OF WRCURL: [online] Available at: http://www.wrc.com/en/wrc/news/october-2016/ vw-withdraws/page/4046--12-12.html. Delete reference

Zhang, B., Veijalainen, J., Kotkov, D. (2016), VW Emission Crisis - Managing Stakeholder Relations on the Web: SCITEPRESS - Science and and Technology Publications, pp. 176187. doi:10.5220/ 0005892401760187. Zhang, B., Veijalainen, J., \& Kotkov, D. (2016). Volkswagen emission crisis: Managing stakeholder relations on the Web. In WEBIST 2016: Proceedings of the 12th International conference on web information systems and technologies. Volume 1, ISBN 978-989-758-186-1. SCITEPRESS.

Zhang, B., Veijalainen, J., Kotkov, D. (2017), Samsung and Volkswagen Crisis Communication in Facebook and Twitter - A Comparative Study., pp. 312-323. DOI: 10.5220/0006301403120323. ISBN: 978-989-758-246-2. Zhang, B., Veijalainen, J., \& Kotkov, D. (2017). Samsung and Volkswagen Crisis Communication in Facebook and Twitter. 